\section{LETTER TO THE EDITOR}

\section{Rifampicin containing antituberculosis medication}

We wish to draw attention to the potential for error in the prescribing and dispensation of antituberculous drugs containing rifampicin.

Most prescriptions for patients with tuberculosis contain rifampicin; this drug must be administered with other chemotherapeutic agents, most commonly isoniazid and pyrazinamide, in order to avoid the emergence of drug resistant organisms. Patient compliance is much improved by the prescription of "combination therapy".

Guidelines for the management of tuberculosis are available ${ }^{1}$ and the drug regimens specified by the Joint Tuberculosis Committee of the British Thoracic Society are published in every issue of the British National Formulary. The Department of Health has recommended "that all cases of tuberculosis should be supervised until treatment has been completed by, or in collaboration with, a consultant with experience in the management of tuberculosis". ${ }^{2}$ Prescribing errors are nevertheless quite frequently observed, some of which have serious consequences; in a recent example we encountered a patient who had received rifampicin alone for a period of some four weeks instead of the triple combination Rifater. It is our purpose here to draw attention to some of the reasons for the occurrence of such errors and how they might be avoided in the future.

A number of rifampicin containing products are available (table 1). The prefix "Rif-" is common to five of these products. Poor handwriting may result in confusion, especially between Rifater and Rifadin or Rifinah as the lengths of the words are very similar. The doses in which Rifadin and Rifinah are likely to be prescribed are also very similar which adds to the confusion.

The numbers attached to the combination products of rifampicin and isoniazid, Rimactazid and Rifinah, are very misleading. Assigning the numbers " 150 " and " 300 " to these products may lead one to believe that two tablets of Rimactazid 150 or Rifinah 150 are equivalent to one tablet of Rimactazid 300 or Rifinah 300, which is not the case. In a pilot survey of nursing staff we found that only 53\% knew that the " 150 " tablets could not be given where the " 300 " tablets had been prescribed.

Many of these drug names start with the same letters and are thus very likely to appear next to each other on the shelves of a dispensary and therefore may easily be confused. The use of corporate packaging may further compound the risk of error-for example, Rimactane and Rimactazid are presented in almost identical packaging.

We would like to make the following suggestions for reducing the risk of such errors:

1. The possibility of error due to similarity in product names should be carefully considered when licensing both trade names and approved names of new drugs.

2. Numbers should not be used to identify tablets. Errors associated with drugs which include a number as part of the name have been reported in the literature. ${ }^{3}$ If a number must be used for the rifampicin/isoniazid combinations it would be more appropriate to use the ratio of the two ingredients as the descriptor rather than the quantity of only one of the ingredients (Rimactazid 150/100 or Rimactazid 300/150)

3. Companies are increasingly using a "corporate" style for drug packaging. This results in the packaging of different drugs produced by the same manufacturer looking very similar, and different strengths of the same drug difficult to identify. Whilst we accept that there is no substitute for reading the label when dispensing or administering drugs, all parties involved in the drug use process should be aware that "human error" does exist and should work towards minimising that risk.

G F CAVELL Pharmacy Department D C S HUTCHISON Department of Respiratory Medicine, King's College Hospital, London SE5 9RS, UK B C WHITEMAN Optimum Health Services, St Giles Hospital, London SE5 7RN

1 Joint Tuberculosis Committee of the British Thoracic Society. Control and prevention of tuberculosis in the United Kingdom: Code Practice 1994. Thorax 1994;49:1193-1200.

2 Interdepartmental Working Group on Tuberculosis. Recommendations for the prevention and control of tuberculosis at local level. Department of Health and Welsh Office, 1996: 18

3 Davis NM. Medication errors - watch out for misleading chemical names. Am $f$ Nursing 1993;10:14.

Table 1 Rifampicin containing products

\begin{tabular}{|c|c|c|c|c|}
\hline Name & Active constituents & & & Manufacturer \\
\hline \multicolumn{5}{|l|}{ Rifampicin alone } \\
\hline Rifampicin & Rifampicin $150 \mathrm{mg}$ & & & APS, Generics \\
\hline Rifampicin & Rifampicin $300 \mathrm{mg}$ & & & APS, Generics \\
\hline Rifadin & Rifampicin $150 \mathrm{mg}$ & & & $\begin{array}{l}\text { Hoechst Marion } \\
\text { Roussel }\end{array}$ \\
\hline Rifadin & Rifampicin $300 \mathrm{mg}$ & & & $\begin{array}{l}\text { Hoechst Marion } \\
\text { Roussel }\end{array}$ \\
\hline Rimactane & Rifampicin $150 \mathrm{mg}$ & & & Ciba \\
\hline Rimactane & Rifampicin $300 \mathrm{mg}$ & & & Ciba \\
\hline \multicolumn{5}{|c|}{ Two drug combination } \\
\hline Rifinah 150 & Rifampicin $150 \mathrm{mg}$ & Isoniazid $100 \mathrm{mg}$ & & $\begin{array}{l}\text { Hoechst Marion } \\
\text { Roussel }\end{array}$ \\
\hline Rifinah 300 & Rifampicin $300 \mathrm{mg}$ & Isoniazid $150 \mathrm{mg}$ & & $\begin{array}{l}\text { Hoechst Marion } \\
\text { Roussel }\end{array}$ \\
\hline Rimactazid 150 & Rifampicin $150 \mathrm{mg}$ & Isoniazid $100 \mathrm{mg}$ & & Ciba \\
\hline Rimactazid 300 & Rifampicin $300 \mathrm{mg}$ & Isoniazid $150 \mathrm{mg}$ & & Ciba \\
\hline \multicolumn{5}{|c|}{ Three drug combination } \\
\hline Rifater & Rifampicin $120 \mathrm{mg}$ & Isoniazid $50 \mathrm{mg}$ & Pyrazinamide $300 \mathrm{mg}$ & $\begin{array}{l}\text { Hoechst Marion } \\
\text { Roussel }\end{array}$ \\
\hline
\end{tabular}

BOOK REVIEW

Infectious Diseases of the Respiratory Tract. Ellis M, ed. (Pp 605; hardback; $£ 125$ (US\$200)). UK: Cambridge University Press, 1998. ISBN 0521405548.

This book aims to be a comprehensive reference resource for all those involved in the diagnosis and care of patients with respiratory infections and, for the most part, it achieves this aim. It is written by some 27 contributors divided between the fields of infectious disease and respiratory medicine. The majority are from the UK with a few from other parts of the world. The editor has written or co-written 13 of the 30 chapters.

It is divided into three sections: diagnosis, host defence and antimicrobials (four chapters); respiratory infections due to major respiratory pathogens (12 chapters); and major respiratory syndromes (14 chapters). This approach provides a good balance. The first section covers the basic principles of respiratory infection and its management, the second will suit those seeking information about the specifics of a particular infection, and the third deals with the practical realities of the clinical setting of, for example, hospital acquired pneumonia or respiratory infection in children. There is a wealth of detail in each chapter which, for the most part, are well laid out. I enjoyed the section on areas for research in the chapter on pneumococcal pneumonia; it would have been nice to have seen a similar discussion in subsequent chapters and the book might have benefited from a template approach to the chapters on specific pathogens.

My criticisms are minor. I would not recommend reading the book anywhere other than in a well lit room since the font used is small $(8 \mathrm{pt})$ and there are a number of annoying typographical errors. The order of the chapters is a little odd with nontuberculous mycobacteria sandwiched between cytomegalovirus and actinomycosis and tuberculosis three chapters later, and upper respiratory tract infections between cystic fibrosis and infections associated with foreign travel. HIV associated respiratory infections merited more space than the 10 pages of text, especially since there is no separate chapter on pneumocystis.

This is a big book both in size $(22.5 \mathrm{~cm} \times$ $28 \mathrm{~cm}$; weight $3 \mathrm{~kg}$ ) and content to which anyone with an interest in respiratory infection should have access.-ME

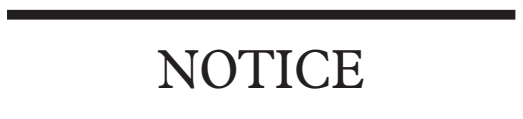

\section{ERSPA-ESPACI Meeting}

The Joint Meeting of the European Respiratory Society Paediatric Assembly (ERSPA) and the European Society of Pediatric Allergy and Clinical Immunology (ESPACI) will be held in Istanbul on 26-29 May 1999. For further information contact Professor Elif Dağll, Bağdat Cad 471/1, Suadiye, Istanbul, Turkey. Telephone: +90216326 6551, +90 216411 9044, +90 216411 9045. Fax: +90216326 $6551, \quad+90 \quad 2164119046 . \quad$ e-mail edagli@superonline.com 